\title{
Ethics Consultation for Adult Solid Organ Transplantation Candidates and Recipients: A Single Centre Experience
}

\author{
Andrew M. Courtwright $(D \cdot \operatorname{Kim}$ S. Erler • Julia I. \\ Bandini • Mary Zwirner • M. Cornelia Cremens • \\ Thomas H. McCoy • Ellen M. Robinson • Emily Rubin
}

Received: 15 January 2020 / Accepted: 3 February 2021 / Published online: 26 February 2021

(C) Journal of Bioethical Inquiry Pty Ltd. 2021

\begin{abstract}
Systematic study of the intersection of ethics consultation services and solid organ transplants and recipients can identify and illustrate ethical issues that arise in the clinical care of these patients, including challenges beyond resource allocation. This was a single-centre, retrospective cohort study of all adult ethics consultations between January 1, 2007, and December 31,2017 , at a large academic medical centre in the north-eastern United States. Of the 880 ethics consultations, sixty (6.8 per cent ) involved solid organ transplant, thirty-nine (65.0 per cent) for candidates and twenty-one (35.0 per cent ) for recipients. Ethics consultations were requested for 4.3 per cent of heart, 4.9 per cent of lung, 0.3 per cent of liver, and 0.3 per cent of
\end{abstract}

\section{A. M. Courtwright}

Department of Pulmonary and Critical Care, Hospital of the University of Pennsylvania, Gates 940, Philadelphia, PA 19102, USA

A. M. Courtwright $(\bowtie) \cdot$ K. S. Erler $\cdot$ M. Zwirner $\cdot$

M. C. Cremens - T. H. McCoy • E. M. Robinson · E. Rubin Optimum Care Committee, Massachusetts General Hospital, Boston, MA, USA

e-mail: Andrew.Courtwright@uphs.upenn.edu

\section{K. S. Erler}

Department of Occupational Therapy, MGH Institute of Health Professions, Boston, MA, USA

J. I. Bandini

RAND Corporation, Boston, MA, USA kidney transplant recipients over the study period. Nurses were more likely to request ethics consultations for recipients than physicians ( 80.0 per cent vs 20.0 per cent, $\mathrm{p}=0.006$ ). The most common reason for consultation among transplant candidates was discussion about intensity of treatment or goals of care after the patient was not or was no longer a transplant candidate. The most common reason for ethics consultation among transplant recipients was disagreement between transplant providers and patients/families/non-transplant healthcare professionals over the appropriate intensity of treatment for recipients. Very few consultations involved questions about appropriate resource allocation. Ethics consultants involved in these cases most often

\section{Zwirner}

Social Service, Massachusetts General Hospital, Boston, MA, USA

M. C. Cremens • T. H. McCoy

Department of Psychiatry, Massachusetts General Hospital, Boston, MA, USA

E. M. Robinson

Patient Care Services, Massachusetts General Hospital, Boston, MA, USA

E. Rubin

Division of Pulmonary and Critical Care Medicine, Massachusetts General Hospital, Boston, MA, USA 
navigated communication challenges between transplant and non-transplant healthcare professionals and patients and families.

Keywords Ethics committee Ethics consultation - Lifesustaining treatment - Organ transplantation - Resource allocation · Transplant recipients

\section{Introduction}

Early ethical questions in solid organ transplantation were often focused on health policy about resource allocation (Kamm 1989; Daniels 1994; Organ Procurement and Transplantation Network 2010; Reese et al. 2010). There is a robust philosophical literature on appropriate organ allocation and decision-making around transplantation, ranging from issues related to duties to rescue versus maximizing life-years saved, altruistic versus paid living donation, cadaveric versus beating heart donors, and health equity versus efficacy (Ross et al. 2012; Veatch et al. 2007; Truog and Miller 2008; Rulli and Millium 2016; Daar 1998; Reese et al. 2010). Increased attention has also been paid to complex ethical questions such as the impact of intellectual and physical disabilities on transplant candidacy as well as access to transplant and post-transplant care for underinsured or undocumented individuals (Richards, Crawley, and Magnus 2009; Wall et al. 2019; Grubbs 2014).

There has been, however, limited systematic study of the intersection between ethics consultation serviceswhich are tasked with assessing and assisting with ethical issues that arise in patient care in the hospital and outpatient settings - and transplant services (Courtwright and Jurchak 2016; Spielman and Verhulst 1997). A finergrained understanding of the interactions between hospital ethics consultation and solid organ transplant candidates and recipients can illuminate broader, policy-level discussions in several ways. First, the actual experience with ethics consultation in this population can reveal unanticipated complexities in organ allocation decisions and the care of transplant candidates and recipients for healthcare professionals, families, and patients. Second, understanding which cases reach the point of ethics consultation and how those cases resolve may provide anticipatory guidance for transplant services (so called preventative ethics) (Foglia et al. 2012; Fox, McGee, and Caplan 1998). Third, because organ-transplantationrelated interventions are often at the leading edge of technology such as extracorporeal membrane oxygenation (ECMO), review of the ethical challenges that arise in the care of candidates and recipients can prepare nontransplant services for when these technologies become more widely available (Meltzer et al. 2016; Courtwright et al. 2016).

The objective of this study was to review our institution's ethics consultation experience with solid organ transplant candidates and recipients.

\section{Methods}

\section{Study Cohort}

This was a single-centre, retrospective cohort study of all adult ethics consultations between January 1, 2007, and December 31, 2017, at Massachusetts General Hospital, a large academic medical centre in the northeastern United States with lung, heart, liver, kidney, and kidney-pancreas transplant services. Cases involving transplant candidates - defined as patients for whom transplant had been raised as a possibility to the point that the transplant service was formally or informally involved in the patient's care, patients who were actively undergoing evaluation, or patients who were actively listed for transplantation - and transplant recipients were included. All other cases were excluded. For contextualization, the total number of transplant recipients, specified by organ type, was identified at our institution over the same time period. Similar data regarding transplant candidates was not available, as we do not track all patients where transplantation is discussed as a possibility but who are not actually evaluated.

Clinical and sociodemographic variables were collected as previously defined (Robinson, Cadge, Erler, et al. 2017a). Briefly, age, race/ethnicity, and primary language were gathered from hospital registration data. Birthplace was identified as either United States (U.S.) (including Puerto Rico and the inhabited territories) or non-U.S. based on birth indexes and medical records. Life-sustaining treatments were defined as medical interventions necessary to prevent or treat major organ dysfunction so as to prevent death (Robinson, Cadge, Erler, et al. 2017a). Decisionmaking capacity related to current medical treatment was assessed by the clinical team, where relevant, at the time of consultation and was categorized as full, fluctuating, or absent. Advance care planning (ACP) documents (defined as healthcare power of attorney, living will, or medical 
orders for life sustaining treatment or related forms) were recorded as present or absent.

Although consultations were often requested on behalf of a care team or group of healthcare professionals, we also recorded the role of the individual actually requesting the ethics consultation. These included physicians (attending, consultant, or house staff), nurses (staff nurse, clinical nurse specialist, nurse manager, and attending nurse), and others (social work, chaplaincy, patients and families, case managers, and physical, occupational, and speech and language therapy). The designation "attending nurse" refers to senior nursing faculty who provide education and support to practicing staff nurses through participation in patient care rounds (Fulmer et al. 2011).

\section{Consultation Themes}

The study authors used an inductive analytic approach to ethics consultation and medical record notes to identify central themes involved in consultation cases as previously described (Robinson et al. 2017a, b; Bandini et al. 2019). Preliminary themes were further revised using iterative sampling whereby the initial consensus categories were reviewed after testing against a random sampling of cases. We subsequently critiqued, revised, and finally agreed on broad thematic categories. Each case was categorized according to the primary theme, with one theme per consultation. Individual cases were selected to illustrate specific ethical concerns. Data were managed using Research Electronic Data Capture (Harris 2009).

\section{Statistical Analysis}

Quantitative data, including differences in select variables between transplant candidate and recipient cases, were analysed using Fisher exact tests for categorical variables and Wilcoxon ranks-sum tests for nonnormally distributed continuous variables (Stata Version 15, Stata Corp, College Station, Texas). The Institutional Review Board approved this study.

\section{Results}

\section{Study Cohort}

Over the eleven-year study period, there were 880 individual ethics consultations. Of these, sixty ( 6.8 per cent $)$ involved solid organ transplant, thirty-nine $(65.0$ per cent ) for candidates and twenty-one (35.0 per cent) for recipients (figure 1). Heart and lung were the most common groups, followed by kidney and liver. There were no consultations for kidney-pancreas candidates or recipients. By way of comparison, there were 185 heart, 164 lung, 566 liver, and 992 kidney transplants performed over the study years. Ethics consultations were requested for 4.3 per cent of heart, 4.3 per cent of lung, 0.3 per cent of liver, and 0.4 per cent of kidney transplant recipients. No patient had multiple consultations regarding separate, distinct ethics concerns.

The majority of candidates and recipients were hospitalized in the intensive care unit (ICU) at the time of consultation (table 1). There was no significant difference in the median number of life-sustaining treatments for candidates compared to recipients (four [interquartile range $(\mathrm{IQR})=1-6]$ vs $4[\mathrm{IQR}=3-6], \mathrm{p}=0.76)$. A significant portion of transplant candidates (74.6 per cent) and recipients (95.2 per cent) lacked decisionmaking capacity or had fluctuating decision-making capacity regarding medical treatment at the time of consultation. A greater proportion of transplant candidates lacked ACP documents compared to transplant recipients (35.9 per cent vs 9.5 per cent, $\mathrm{p}=0.03$ ).

Nurses originated 80.0 per cent of ethics consultations for transplant recipients compared to 40.5 per cent of consultations for transplant candidates (table 2). Nurses were significantly more likely to request ethics consultations than physicians for transplant recipients $(\mathrm{p}$ $=0.006$ ). There was no difference in median time from admission to ethics consultation in candidates versus recipients (nineteen days (IQR $=4-41)$ vs 30 (IQR = $6-52), \mathrm{p}=0.40)$.

\section{Consultation Requests in Candidates}

\section{Goals of Care after Transplant Not Possible}

The most common reason for consultation among transplant candidates was ongoing discussion about intensity of treatment or goals of care after the transplant team determined that the patient was not or was no longer a transplant candidate (figure 2). Within this category there were a number of additional themes (table 3 ). In five cases, ethics consultation was requested to help navigate conflict centred on patient statements-most commonly requests for full code status or to "do everything" - made before he or she was determined not to be a transplant candidate. In these cases, patients no longer 


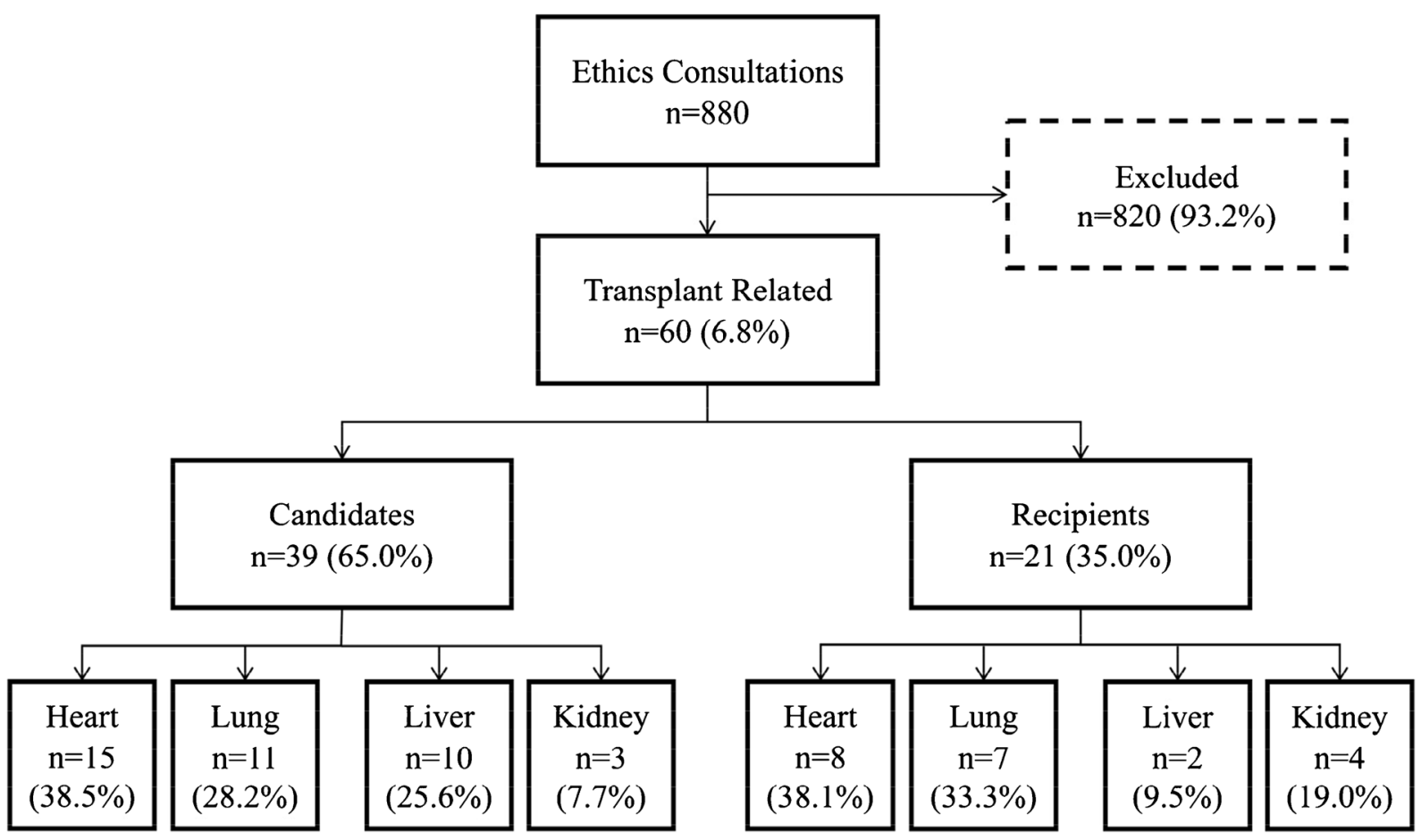

Fig. 1 Study cohort

had decision-making capacity and surrogates continued to request full code status or ongoing life-sustaining treatments such as mechanical ventilation because of the prior statements. For example, a fifty-one-year-old woman with polycystic kidney disease on dialysis was admitted with seizures and a cardiac arrest. She had made significant financial and personal sacrifices to work toward being a kidney transplant recipient. Because of her poor prognosis, including persistent ventilator dependent respiratory failure, she was no longer a transplant candidate. Her family, however, wanted to honour her prior aggressive goals and requested cardiopulmonary resuscitation (CPR) in the event of another arrest. In these cases, ethics consultations worked to frame prior requests in the light of new clinical information, focusing on what the patient would want now that transplant was no longer possible.

In three cases, ethics consultation was requested for patients who had consistently been non-adherent with the medical requirements necessary to reach transplant (such as alcohol use cessation, demonstration of consistent outpatient follow-up with the pre-transplant team, or medication adherence for heart failure management) and were no longer transplant candidates. These patients (and, in two cases, surrogates) continued to request other interventions as they developed end-stage organ failure, such as full code status, ongoing continuous renal replacement therapy for hepatorenal syndrome, or intubation in the event of respiratory compromise. There was frustration among the medical team that they were or would be "required" to provide these interventions even though the patient had not done what had been recommended to avoid being in these clinical circumstances. There was often anger among surrogates that the transplant team had abandoned the patient or had not given enough resources or chances for him or her to be adherent to treatment recommendations. Some surrogates felt that continued dialysis or a trial of mechanical intubation would provide time to demonstrate that the patient could become a transplant candidate despite the transplant team's decision.

In five cases, ethics consultation was requested to navigate disagreement between the medical team and family over whether enough time has passed to say a trial of advanced therapies such as mechanical ventilation or ECMO had failed. In these cases, there was often agreement that the patient would not want to be kept alive if there was no hope for meaningful recovery. There was, however, epistemic disagreement about whether the patient could ever improve to the point that 
Table 1 Characteristics of solid organ candidates and recipients for whom an ethics consultation was requested

\begin{tabular}{|c|c|c|}
\hline & Candidates $(\mathrm{n}=39)$ & Recipients $(n=21)$ \\
\hline Age, y median (IQR) & $53(30-60)$ & $59(50-65)$ \\
\hline Female, $\mathrm{n}(\%)$ & $17(43.6)$ & $4(19.0)$ \\
\hline Non-White race/ethnicity, n(\%) & $10(25.6)$ & $1(4.8)$ \\
\hline Non-English primary language, $\mathrm{n}(\%)$ & $3(7.7)$ & $1(4.8)$ \\
\hline \multicolumn{3}{|l|}{ Transplant organ, $\mathrm{n}(\%)$} \\
\hline Heart & $15(38.5)$ & $8(38.1)$ \\
\hline Lung & $11(28.2)$ & $7(33.3)$ \\
\hline Liver & $10(25.6)$ & $2(9.5)$ \\
\hline Kidney & $3(7.7)$ & $4(19.0)$. \\
\hline \multicolumn{3}{|l|}{ Hospitalized in intensive care unit, $\mathrm{n}(\%)$} \\
\hline Intensive care unit, $\mathrm{n}(\%)$ & $32(82.1)$ & $19(90.5)$ \\
\hline Inpatient non-intensive care unit, $\mathrm{n}(\%)$ & $7(17.9)$ & $2(9.5)$ \\
\hline Full decision-making capacity, n(\%) & $10(25.6)$ & $1(4.8)$ \\
\hline Fluctuating decision-making capacity, n(\%) & $9(23.1)$ & $5(23.8)$ \\
\hline Number of life-sustaining treatments, median (IQR) & $4(1-6)$ & $4(3-6)$ \\
\hline Continuous renal replacement therapy, n(\%) & $12(30.8)$ & $6(28.6)$ \\
\hline Intermittent renal replacement therapy, $\mathrm{n}(\%)$ & $3(7.7)$ & $2(9.5)$ \\
\hline Mechanical ventilation, $\mathrm{n}(\%)$ & $19(48.7)$ & $14(66.6)$ \\
\hline Extracorporeal membrane oxygenation, n(\%) & $14(35.9)$ & $7(33.3)$ \\
\hline Ventricular assist device, $\mathrm{n}(\%)$ & $5(12.8)$ & $0(0.0)$ \\
\hline Artificial nutrition and hydration, $\mathrm{n}(\%)$ & $16(41.0)$ & $12(57.1)$ \\
\hline Vasopressor, $\mathrm{n}(\%)$ & $23(59.0)$ & $12(57.1)$ \\
\hline Blood product transfusions, $\mathrm{n}(\%)$ & $14(35.9)$ & $9(42.9)$ \\
\hline
\end{tabular}

he or she would become a transplant candidate or improve to the point that transplant was no longer necessary. For example, a forty-three-year-old with rapidly progressive interstitial lung disease was transferred to the ICU on ECMO for lung transplant evaluation. When the transplant committee determined that he was not a candidate, he was maintained on ECMO as a bridge to recovery to allow a trial of augmented

Table 2 Ethics consultant characteristics among solid organ transplant candidates and recipients

\begin{tabular}{|c|c|c|c|}
\hline & Candidates $(n=39)$ & Recipients $(n=21)$ & P-value \\
\hline Duration of hospitalization prior to consult, $\mathrm{d}$ median (IQR) & $19(4-41)$ & $30(6-52)$ & 0.40 \\
\hline Consult requestor, $\mathrm{n}(\%)$ & & & $0.006^{*}$ \\
\hline Attending physician & $12(20.8)$ & $2(9.5)$ & \\
\hline Consulting physician & $1(2.6)$ & $0(0.0)$ & \\
\hline House staff physician & $9(23.1)$ & $2(9.5)$ & \\
\hline $\begin{array}{l}\text { Attending nurse, clinical nurse } \\
\text { specialist, or nurse } \\
\text { manager }\end{array}$ & $13(33.3)$ & $13(61.9)$ & \\
\hline Staff nurse & $1(2.6)$ & $3(14.3)$ & \\
\hline Other & $3(7.7)$ & $1(4.8)$ & \\
\hline No advance care planning documents, $\mathrm{n}(\%)$ & $14(35.9)$ & $2(9.5)$ & 0.03 \\
\hline
\end{tabular}

* p-value for comparison of total nurse- versus total physician-originated ethics consultation. 


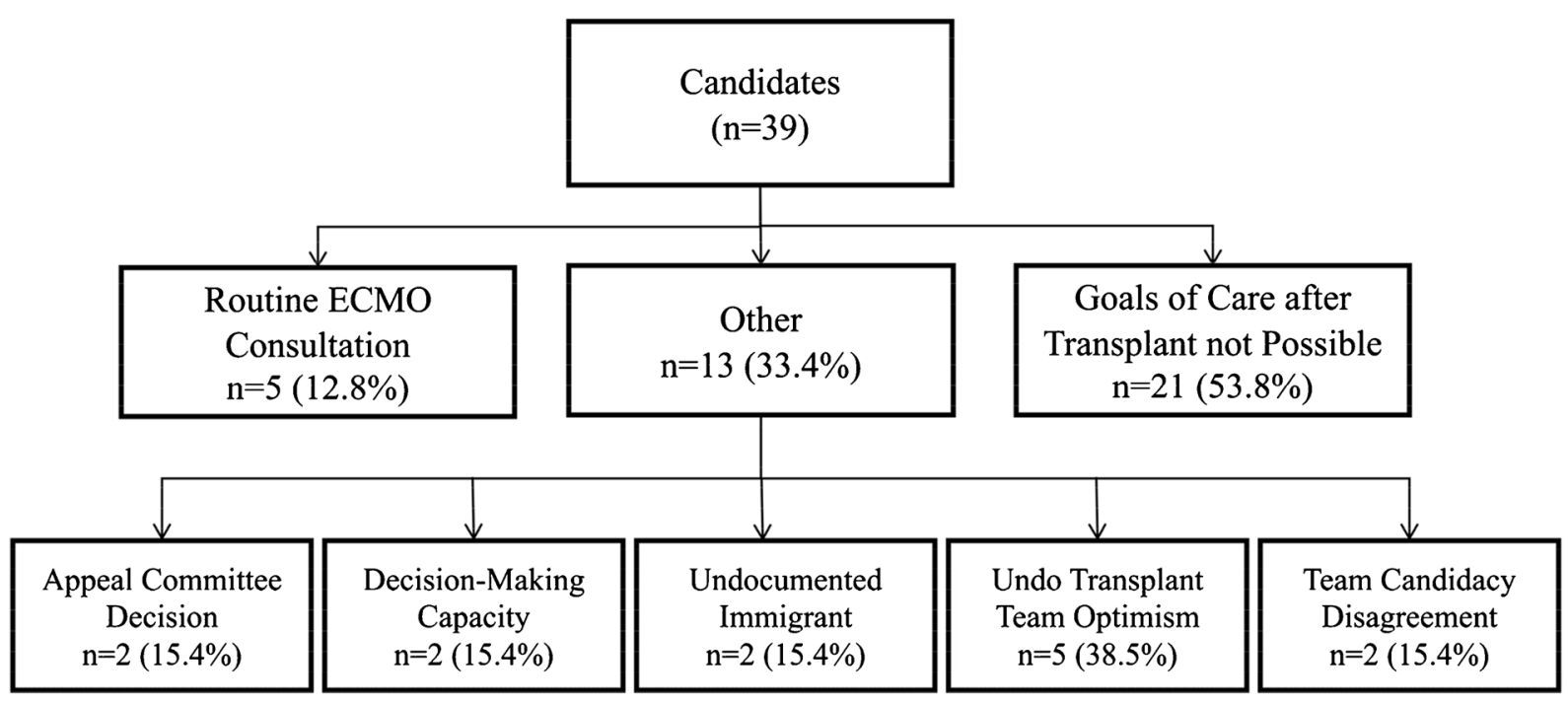

Fig. 2 Reasons for ethics consultation requests amongst solid organ transplant candidates

immunosuppression. When he failed to improve and developed recurrent infections, the ICU team

Table 3 Additional themes among ethics consultation requests regarding goals of care after determination patient was not or was no longer a transplant candidate

\begin{tabular}{|c|c|}
\hline & $\begin{array}{l}\text { Cases } \\
(\mathrm{n}=21)\end{array}$ \\
\hline $\begin{array}{l}\text { Interpreting earlier patient statements requesting full } \\
\text { code status/continuing life-sustaining treatment } \\
\text { now that transplant is not possible, } \mathrm{n}(\%)\end{array}$ & $5(23.8)$ \\
\hline $\begin{array}{l}\text { Disagreement between medical team and family over } \\
\text { whether enough time has passed to say a trial of } \\
\text { advanced therapies has failed, n }(\%)\end{array}$ & $5(23.8)$ \\
\hline $\begin{array}{l}\text { Patient not adherent to treatment plan required for } \\
\text { transplant candidacy but also requesting full code } \\
\text { status and/or intensive interventions at end of life, } n \\
(\%)\end{array}$ & $3(14.3)$ \\
\hline $\begin{array}{l}\text { Medical team requesting support in discussing } \\
\text { decision to inactive patient because of severity of } \\
\text { illness, } \mathrm{n}(\%)\end{array}$ & $3(14.3)$ \\
\hline $\begin{array}{l}\text { Other: concern about factitious disorder by proxy } \\
\text { impacting non-transplant care plan after patient } \\
\text { declined for transplant, } \mathrm{n}(\%)\end{array}$ & $1(4.8)$ \\
\hline $\begin{array}{l}\text { Other: physician conscientious objection to } \\
\text { pacemaker deactivation after patient no longer a } \\
\text { transplant candidate, } \mathrm{n}(\%)\end{array}$ & $1(4.8)$ \\
\hline $\begin{array}{l}\text { Other: medical team requesting trial of additional } \\
\text { therapies to revisit transplant candidacy but family } \\
\text { declining on patient's behalf, } \mathrm{n}(\%)\end{array}$ & $1(4.8)$ \\
\hline $\begin{array}{l}\text { Other: non-transplant team concerned about ongoing } \\
\text { utilization of extracorporeal liver assist device after } \\
\text { patient no longer a transplant candidate, } \mathrm{n}(\%)\end{array}$ & $1(4.8)$ \\
\hline $\begin{array}{l}\text { Other: end of life decision-making for patient without } \\
\text { available surrogate decision-maker, } \mathrm{n}(\%)\end{array}$ & $1(4.8)$ \\
\hline
\end{tabular}

determined that ECMO should be withdrawn. His family requested ongoing ECMO support to see if additional time and further immunosuppression would allow him to be safely decannulated. In some of these cases, there was distrust among surrogates that healthcare professionals had really tried all reasonable therapies. Surrogates also appeared to struggle with what they perceived as an abrupt transition from an extremely aggressive, restorative focus to a more palliative approach.

In some cases, ethics consultants worked with healthcare teams and transplant professionals to frame do-not-resuscitate status or limitation of life-sustaining treatment as a medical recommendation rather than a shared decision. This was particularly true in cases where all options felt to be appropriate medically had been exhausted. In these conversations, acknowledging the "transplant journey," with an emphasis on the patient's transplant candidacy-related experiences appeared to open discussions about transitioning to a palliative approach. In other cases of intractable conflict, ethics consultants discussed the appropriateness of not offering CPR despite patient or surrogate requests, in accordance with hospital policy (Courtwright et al. 2015; Robinson, Cadge, Zollfrank, et al. 2017b). In almost all cases of conflict over goals of care, families agreed with medical recommendations, and lifesustaining treatment was withdrawn or not escalated in the face of ongoing decline. For four patients, there was persistent conflict. In the first case, ECMO was continued and the patient was transferred to another institution and transplanted. In a second case, the patient was 
transferred to a long-term acute care hospital with full code status and suffered a cardiac arrest with unsuccessful resuscitation. In a third case, the patient had an in-hospital cardiac arrest and underwent successful resuscitation with neurologic injury. His family subsequently requested lifesustaining treatment be withdrawn. In a fourth case involving a patient on ECMO, surrogates initially contacted a lawyer to file an injunction against ECMO withdrawal. After further discussion with the medical and ethics consultation service, they assented to ECMO cessation and the patient passed away shortly thereafter.

\section{Routine ECMO Consultation}

The second most common category among candidates involved patients who received an ethics consultation as part of our institution's policy of routine ethics consultation for all ECMO patients (Courtwright et al. 2016). In these five cases, no specific ethical issue was identified. The consultation service primarily provided support for candidates or potential candidates and their families while they waited for organ offers or recovery, respectively.

\section{Other Reasons for Consultation}

The remaining fourteen consultations included two cases in which ethics involvement was requested as a mechanism for appealing the transplant team's decision about candidacy. In these situations, the committee declined the specific consultation, directing patients/ families to other resources such as the Office for Civil Rights and the United Network for Organ Sharing Operations and Safety Committee or referring them for second opinions at other centres (Health and Human Services Press Office 2019). Consultants, however, offered to participate in a more general review of ethical consideration regarding transplant candidacy with individual organ transplant committees.

There were two cases in which ethics consultation was requested for potential heart transplant candidates whose immigration status was a barrier to listing. In one case, a man who had come to the United States twenty-four years earlier developed progressive heart failure. Because of his undocumented immigrant status, his options for insurance coverage were extremely limited, which impacted his candidacy, particularly regarding post-transplant medication costs. In another case, a young East Asian woman was studying in Boston on a student visa when she developed an idiopathic myocarditis with subsequent cardiac arrest.
She had minimal recovery of heart function despite ECMO support, and transplant evaluation was initiated. The ethics consultants and the team discussed stewardship of organs when the candidate's financial and social circumstances are uncertain, rights to care, and whether that includes organ transplantation, and justice regarding the fact that the health system would have accepted her as an organ donor regardless of her immigration status. Ultimately, through the efforts of social workers and the transplant team, a framework was put in place to allow her to have short-term insurance/financial support. She was successfully transplanted and continues to do well.

In five cases (three lung, one heart, and one liver), an ethics consultation was requested because of a perception among non-transplant healthcare professionals that transplant physicians were being unduly optimistic about the ability of the patient to become a transplant candidate. For example, a fifty-seven-year-old man with restrictive cardiomyopathy was admitted with progressive heart failure. He was hospitalized for three months with ongoing complications, including worsening kidney disease, recurrent pneumonia, and pressure ulcers causing severe pain. The cardiac ICU team felt that he would not ever improve significantly and that undue optimism from the transplant providers was causing the patient to suffer. Eventually he developed an episode of septic shock, which was felt to be irreversible, and life-sustaining treatment was withdrawn. In a similar case, a fifty-five-year-old woman with hepatitis $\mathrm{C}$ and alcoholic cirrhosis had a prolonged hospitalization with multiple complications from end-stage liver disease. Although the transplant committee determined she was not a candidate because she was "too sick," they identified a list of requirements that she would need to meet in order to be reconsidered. Non-transplant professionals felt that, based on their experience, these goals were not realistic and requested an ethics consultation to mediate conflict with the patient's husband, who asked for ongoing intensive interventions to allow her to be reconsidered for transplant. She also passed away from infectious complications shortly after the consultation.

Consultation Requests in Recipients

Recent Transplant-Physicians Requests More Treatment Than Patient/Surrogate/ICU team

The most common reason for ethics consultation among transplant recipients was disagreement between 
transplant providers and patients/families/non-transplant healthcare professionals over the appropriate intensity of treatment for recipients with recent transplants (most often in their first-post transplant year) (figure 3). In these cases, transplant teams recommended continuation or escalation of interventions that patients/ surrogates or non-transplant physicians felt were inappropriate given the recipient's overall trajectory or anticipated prognosis. There was often substantial alignment between families/patients and the non-transplant teams, and it was often unclear from the medical record whether one voice was "driving" the conversation to a greater extent. As such, we did not further separate these cases into ones where patients/families were declining ongoing treatment versus non-transplant providers. For example, an attending nurse requested an ethics consultation for a fifty-eight-year-old heart transplant recipient who had developed pulmonary mucormycosis, an invasive fungal infection with an extremely poor prognosis. He had already undergone a thoracotomy and removal of two ribs to help control the infection and was facing additional surgeries in the setting of progressive renal failure from antifungal medications. His wife did not feel that his chances of recovery were sufficient to justify ongoing invasive treatments, a judgement that the critical care team supported, but the transplant team recommended additional surgery. Similarly, an ethics consultation was requested for a liver transplant recipient who had recurrent hepatitis $\mathrm{C}$ virus (HCV) liver injury five months after transplant. She had worsening graft failure despite $\mathrm{HCV}$ treatment, including severe encephalopathy. Her family, with the support of the medical intensive-care unit team, did not feel that she would want to continue treatment given her expected quality of life. The transplant team argued that there were still additional antiviral treatments that should be attempted.
Nurses requested the majority of these consultations (81.2 per cent ), although the decision to contact the ethics service was often based on multidisciplinary consensus. In many of these cases, there was a perception among families and non-transplant professionals that the transplant team's recommendations were not fully patient-centred, influenced instead by one-year survival metrics (Courtwright et al. 2019). Ethics consultants played multiple roles in these cases, most commonly organizing a transplant/non-transplant team meeting or a team/family meeting. In these meetings, absent full consensus on treatment trajectory, consultants sought to identify benchmarks for time-limited trials and weigh hope for recovery against realism about a meaningful quality of life. Discussions also focused on how to mitigate moral distress among the care team in the presence of uncertainty about prognosis. In some cases, transplant professionals resisted ethics involvement, perceiving that consultants did not have enough experience with positive transplant outcomes. Palliative care was involved in three (18.7 per cent ) of these sixteen cases. The role of palliative care was most often symptom management, either before or after goals of care had been agreed upon. In about a third of cases, lifesustaining treatment was withdrawn immediately following goals of care meetings. In some cases, such as the heart transplant recipient with mucormycosis, the patient improved and was successfully discharged home. In three other cases patients recovered to the point that they were able to be discharged to acute rehabilitation or skilled nursing facilities.

Remote Transplant-Patient/Surrogate Requests More Treatment Than Medical Team

Three consultation requests involved surrogates of transplant recipients who refused limitation of life-

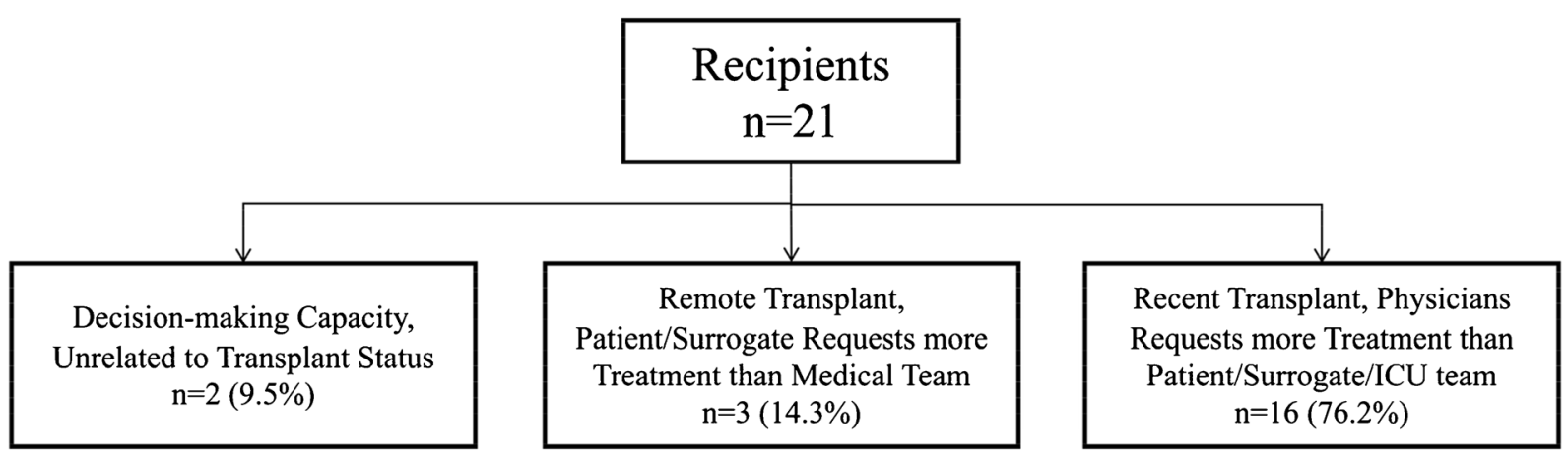

Fig. 3 Reasons for ethics consultation requests amongst solid organ transplant recipients 
sustaining treatment despite consensus among transplant and non-transplant healthcare professionals that ongoing treatment was inappropriate. Most of these recipients were several years from transplant. In one case - a twenty-one-year-old heart transplant recipient who was in a persistent vegetative status following severe anoxic brain injury a year and half after his transplant - the ethics consultants mediated conflict over DNR status as the patient began to develop septic shock with multisystem organ failure. In this case, consultants recommended not offering CPR, consistent with institutional policies, and the patient passed away without resuscitation (Courtwright et al. 2015).

\section{Decision-Making Capacity-Unrelated to Transplant Status}

The final two cases involved recipients with unclear decision-making capacity. One case involved a kidney transplant recipient who was non-adherent with dialysis after his graft failed, and questions were raised about his capacity to refuse dialysis. The other case involved a kidney transplant recipient with intermittent delirium whose wife and mother disagreed about the appropriate level of treatment. The medical team requested an ethics consultation to help evaluate whether he had capacity to designate a formal healthcare agent. In both cases, the fact that the patients had had transplants was incidental to the consultation.

\section{Discussion}

In reviewing eleven years of ethics consultation for transplant candidates and recipients at a large academic hospital with multiple solid organ transplant programmes, our primary findings were as follows. First, ethics consultation for transplant candidates most often involved conflict over treatment intensity once transplant was no longer a possibility. Second, ethics consultations for transplant recipients primarily involved disagreement between surrogates and healthcare professionals, including nurses, and transplant and nontransplant teams over intensity of treatment. Third, there were a range of ethical issues that arose in the care of transplant candidates and recipients other than disagreement over ongoing life-sustaining treatment.

Past studies regarding ethics consultation for transplant candidates and recipients have focused on specific requests or challenging cases such as living organ donation from individuals with developmental delay (Spike 2001), novel organ transplant procedures such as face transplant or uterine transplant (Castlen and Cochrane 2019), withdrawing ECMO for patients who are awake and alert but who are not transplant candidates (DeMartino 2019), discussion of burdens and benefits of transplant in paediatric populations (Aulisio et al. 2009), or candidacy denials because of illicit drug use (Ryan et al. 2019). More commonly, ethics committees may function as a discussion forum for individual programmes when considering listing (or inactivation) policies (Thomas et al. 2015). Our experience expands on this work by systematically illustrating the varied ways that the consultation service may interact with the care of transplant candidates and recipients.

We found that ethics consultation was more common for heart and lung transplant recipients compared to kidney or liver recipients. This may be a function of the relative complexity, longer hospital, and illness severity for heart and lung recipients (Courtwright et al. 2019). Overall, 6.8 per cent of all ethics consultations at our institution involved solid organ candidates or recipients. This was a higher percentage than other "traditional" ethics consultation populations/questions such as patients without surrogates (3.8 per cent over the same study period), interpretation of advanced care planning documents (2.9 per cent ), or cases involving substance use disorders (4.0 per cent ). Unfortunately, we are not aware of systematic studies from other centres that provide sufficient detail on transplant-related consultations to allow us to assess whether ethics consultations were unexpectedly (in)frequent in our population. The study years did overlap with a period in which the palliative care service was also growing at our institution. Some cases that may have resulted in ethics consultation in earlier years may have been referred to palliative care over time. We note, however, that palliative care involvement was relatively infrequent in these cases aside from end-of-life symptom management (Colman et al. 2013). In our cohort, this may reflect the fact that ethics consultants mediated the misalignment in goals of care without necessitating palliative care. Nevertheless, there is a growing literature supporting palliative care involvement for transplant recipients (Colman et al. 2015).

Communication was an essential feature of many of the ethics consultations for candidates and recipients. It was particularly central in cases involving goals of care 
after transplantation was no longer possible, concerns about undue transplant team optimism, and disagreement about ongoing or escalating life-sustaining treatment for transplant recipients. In these cases, there was often a perceived breakdown in communication that led to concerns about the most appropriate plan of care for the patient. For example, some families felt unprepared for the decision that their loved one was not or was no longer a candidate for transplant. This perceived abrupt transition in aggressiveness of treatment-from transplant to end-of-life — was sometimes perceived as "giving up" on the patient. This, in turn, contributed to conflict over continuing life-sustaining treatment, particularly in cases in which expectations surrounding transplant candidacy had not been explicitly communicated or in which families had unrealistic goals regarding transplant.

In other cases, ethics consultants were involved with patients who appeared to be in transplant limbo-not currently candidates but not definitely ruled out as candidates. In some of these cases, there was a perception among non-transplant healthcare professionals that even the transplant team did not really believe that the patient would be a candidate. Non-transplant teams raised concerns that transplant teams were being unrealistic or were just waiting for another clinical event to make a candidacy decision for them. In contrast, transplant teams expressed genuine uncertainty as to whether the patient could make it to transplant but wanted to provide every opportunity to reach this goal. When there was a perceived lack of transparency concerning the appropriate plan of care, open discussion about the possibility and hope for transplant helped to identify common ground, including time limited trials of ongoing support.

Another source of communication challenges was related to the idea of consent for transplant. We observed that the transplant team often conceptualized consent on a "surgical buy-in" model whereby patients consent not only for the transplant itself but for all the steps necessary for a successful transplant outcome (Schwarze, Bradley, and Brasel 2010). In contrast, some patients and families felt that they had not agreed to additional interventions such as dialysis or prolonged mechanical ventilation, particularly if these were perceived to be particularly burdensome. The clash between these two ideas of consent led to frustration on the part of transplant providers, who sometimes felt that patients were not fulfilling their end of the agreement. This may, capture, in part, why patient/family requests to withdraw life-sustaining treatments, which may have been perceived as reasonable in other contexts, rose to the level of ethics consultation. In these cases, ethics consultants felt that it was helpful to openly acknowledge the different frameworks of consent that were at play and how this impacted what clinical recommendations were being made.

In cases in which the transplant team recommended ongoing or escalating life-sustaining treatment that nontransplant professionals felt was inappropriate, there was sometimes a concern that regulatory benchmarks rather than patient-centred care were guiding these recommendations. This may be one explanation for why nursing consultation requests were more common among transplant recipients, particularly those within their first year. In their bedside role, clinical nurses may be more attuned to patient suffering and the burdens imposed by ongoing or escalating interventions (Gutierrez 2005). In addition, clinical nurses may be more aware of breakdowns in communication that occur because of multiple conversations with different services throughout the day, where different messages may be conveyed (Weinzimmer et al. 2014). Family members may also be more comfortable expressing their concerns about the patient's trajectory away from the transplant team, to whom they may feel particularly indebted.

\section{Recommendations}

We have several recommendations, based on our experience in these cases, to improve communication and expectations around the care of transplant candidates and recipients. With regard to potential transplant candidates, particularly those transferred from other institutions, it is very important that ACP start at the time of transfer. Conversations about the transplant evaluation and listing criteria should also include discussion with the patient about goals of care if transplant is not possible. ACP documents were not present for more than a third of candidates in our cohort. This suggests room for improvement, particularly as subsequent discussions about life-sustaining treatment may sometimes be easier when the voice of the patient can be introduced. We also recommend instruments from the surgical decisionmaking literature such as the best case/worst case tool to help guide ACP planning (Kruser et al. 2017). Equally important, we recommend that transplant and nontransplant health professionals set clear criteria 
regarding inactivation as well as specific benchmarks for listing/reactivation. While flexibility is important in evolving clinical scenarios, shifting goals and a perceived lack of transparency may increase moral distress among non-transplant providers and patients/families. With regard to transplant recipients, a shared conception of transplant consent, including decision-making when successful post-transplant outcomes no longer appear possible, is essential prior to the transplant surgery itself (Courtwright et al. 2019).

We also recommend developing opportunities for non-transplant health professionals to observe transplant-related activities outside of routine clinical care. This could include having ICU nursing and physician leadership attending transplant committee meetings, particularly for organ systems such as heart or lung where ethics consultation requests are more common. In our experience, integration of non-transplant leaders into transplant quality assurance and performance improvement (QAPI) programmes, which are mandated by the Center for Medicare and Medicaid Services, provides an opportunity for learning about transplant regulatory metrics as well as internal programmatic processes. At the same time, because many QAPIs focus on the care of hospitalized transplant candidates and recipients, the presence of non-transplant teams allows closer clinical collaboration.

Finally, we have observed that opportunities for unitbased discussion of ethical issues in transplant patients may provide a forum for giving voice to ethical concerns before formal ethical consultation is needed (Pavlish et al. 2018). These may take the form of ethics rounds, in which a member of the consultation team periodically joins the primary service during daily clinical rounds; ethics conferences, in which a consultant is periodically available on the unit to informally discuss active cases; or ethics morbidity and mortality rounds, in which consultants meet with transplant and non-transplant professionals to formally review complex ethical cases with the goal of identifying learning points for future patients (Stahl, Siddiqui, and Sadovnikoff 2017; Snelgrove, Ng, and Devon 2016).

\section{Limitations}

Our study has several limitations. First, because this is a single centre study with an active transplant group and ethics consultation service, our findings may not generalize to smaller centres or to hospitals where other teams, such as palliative care, are integrated into the care transplant patients (Larson and Curtis 2006; Potosek et al. 2014). In addition, we do not have data for direct comparison among all transplant recipients to identify whether there are specific factors such as older age that are disproportionately represented among ethics consultation cases. Second, although the study authors were closely involved in these consultations, this was a retrospective medical record review. We are, therefore, lacking the direct voice of patients, family members, and various healthcare professionals in how they experienced the events leading up to the consultation and the consultation process itself. Prospective qualitative data collection would add an important dimension to this research. This is particularly true for consultations involving people of colour, where direct patient and family perspectives on issues such as systemic racism and access to transplant and post-transplant care are essential. Third, we have not studied the impact of the strategies we have observed in navigating ethics consultation for transplant candidates and recipients. Such research is notably lacking in the ethics consultation literature more generally. Transplant patients would be a potentially attractive study population given the complexities of the ethical issues in these cases.

\section{Conclusions}

The ethical issues encountered in the care of transplant candidates and recipients extend beyond traditional concerns involving resource allocation. Ethics consultants involved in these cases often navigate communication challenges between transplant and non-transplant healthcare professionals and patients and families.

\section{References}

Aulisio, M.P., J. Moore, M. Blanchard M. Bailey, and D. Smith. 2009. Clinical ethics consultation and ethics integration in an urban public hospital. Cambridge Quarterly of Healthcare Ethics 18(4): 371-383.

Bandini, J.B., A.M. Courtwright, E. Rubin, et al. 2019. Ethics consultations related to opioid use disorder. Psychosomatics 61(2): 161-170.

Castlen, J.P., and T.I. Cochrane. 2019. Ethics committees, innovative surgery, and organizational ethics. In Ethics of innovation in neurosurgery, edited by M.L.D. Broekman, 105112. New York City: Springer Publishing Company. 
Colman, R.E., J.R. Curtis, J.E. Nelson, et al. 2013. Barriers to optimal palliative care of lung transplant candidates. Chest 143(3): 736-743.

Colman, R., L.G. Singer, R. Barua, and J. Downar. 2015. Characteristics, interventions, and outcomes of lung transplant recipients co-managed with palliative care. Journal of Palliative Medicine 18(3): 266-269.

Courtwright, A.M., S. Brackett, W. Cadge, E.L. Krakauer, and E. Robinson. 2015. Experience with a hospital policy on not offering cardiopulmonary resuscitation when believed more harmful than beneficial. Journal Critical Care 30(1): 173177.

Courtwright A., and M. Jurchak. 2016. The evolution of American hospital ethics committees: A systematic review. The Journal of Clinical Ethics 27(4): 322-340.

Courtwright, A.M., E.M. Robinson, K. Feins, et al. 2016. Ethics committee consultation and extracorporeal membrane oxygenation. Annals of the American Thoracic Society 13(9): 1553-1558.

Courtwright, A.M., E. Rubin, E.M. Robinson, et al. 2019. An ethical framework for the care of patients with prolonged hospitalization following lung transplantation. HEC Forum 31(1): 49-62.

Daar, A.S. 1998 Paid organ donation - the grey basket concept. Journal of Medical Ethics 24(6): 365-368.

Daniels, N. 1994. Four unsolved rationing problems: A challenge. The Hastings Center Report 24(4): 27-29.

DeMartino, E.S., N.A. Braus, D.P. Sulmasy, et al. 2019. Decisions to withdraw extracorporeal membrane oxygenation support: Patient characteristics and ethical considerations. Mayo Clinic Proceedings 94(4): 620-627.

Foglia, M.B., E. Fox, B. Chanko, and M.M. Bottrell. 2012. Preventive ethics: Addressing ethics quality gaps on a systems level. The Joint Commission Journal on Quality and Patient Safety 38(3): 103-107.

Fox, M.D., G. McGee, A. Caplan. 1998. Paradigms for clinical ethics consultation practice. Cambridge Quarterly of Healthcare Ethics 7(3): 308-314.

Fulmer, T., E. Cathcart, K. Glassman, W. Budin, M. Naegle, and N. Van Devanter. 2011. The attending nurse: An evolving model for integrating nursing education and practice. The Open Nursing Journal 5: 9-13.

Grubbs, V. 2014. Undocumented immigrants and kidney transplant: Costs and controversy. Health Affairs 33(2): 332-335.

Gutierrez, K.M. 2005. Critical care nurses' perceptions of and responses to moral distress. Dimensions of Critical Care Nursing 24(5): 229-241.

Harris, P.A., R. Taylor R. Thielke, J. Payne, N. Gonzalez, and J.G. Conde. 2009. Research electronic data capture (REDCap)A metadata-driven methodology and workflow process for providing translational research informatics support. Journal of Biomedical Informatics 42(2): 377-381.

Health and Human Services Press Office. 2019. OCR resolves disability complaint of individual who was denied the opportunity for heart transplant list placement. Last modified February 2019. https://www.hhs.gov/about/news/2019/02 /12/ocr-resolves-disability-complaint-individual-who-wasdenied-opportunity-heart-transplant-list.html. Accessed December 16, 2019.
Kamm, F.M. 1989. The report of the US Task Force on Organ Transplantation: Criticisms and alternatives. The Mount Sinai Journal of Medicine 56(3): 207-220.

Kruser, J.M., L.J. Taylor, T.C. Campbell, et al. 2017. "Best case/ worst case": Training surgeons to use a novel communication tool for high-risk acute surgical problems. Journal of Pain and Symptom Management 53(4): 711-719.

Larson, A.M., and J.R. Curtis. 2006. Integrating palliative care for liver transplant candidates: "Too well for transplant, too sick for life". Journal of the American Medical Association 295(18): 2168-2176.

Meltzer, E.C., N.S. Ivascu, M. Stark, et al. 2016. A survey of physician attitudes toward decision-making authority for initiating and withdrawing VA-ECMO: Results and ethical implications for shared decision-making. The Journal of Clinical Ethics 27(4): 281-289.

Organ Procurement and Transplantation Network. 2010. Ethical principles in the allocation of human organs. Last modified June 2016 . https://optn.transplant.hrsa. gov/resources/ethics/ethical-principles-in-the-allocation-ofhuman-organs/. Accessed December 16, 2019.

Pavlish, C.L., E.M. Robinson, K. Brown-Saltzman, and J. Henriksen. 2018. Moral distress research agenda. In Moral distress in the health professions, edited by C.M. Ulrich and C. Grady, 103-125. New York City: Springer Publishing Company.

Potosek, J., M. Curry M. Buss, and E. Chittenden. 2014. Integration of palliative care in end-stage liver disease and liver transplantation. Journal of Palliative Medicine 17(11): 1271-1277.

Reese, P.P., A.L. Caplan, R.D. Bloom, P.L. Abt, and J.H. Karlawish. 2010. How should we use age to ration health care? Lessons from the case of kidney transplantation. Journal of the American Geriatrics Society 58(10): 1980 1986.

Richards, C.T., L.M. Crawley, and D. Magnus. 2009. Use of neurodevelopmental delay in pediatric solid organ transplant listing decisions: Inconsistencies in standards across major pediatric transplant centers. Pediatric Transplantation 13(7): 843-850.

Robinson, E.M., W. Cadge, K. Erler et al. 2017a. Structure, operation, and experience of clinical ethics consultation 2007-2013: A report from the Massachusetts General Hospital Optimum Care Committee. The Journal of Clinical Ethics 28(2): 137-152.

Robinson, E.M., W. Cadge, A. Zollfrank, M.C. Cremens, and A.M. Courtwright. 2017b. After the DNR: Surrogates who persist in requesting cardiopulmonary resuscitation. Hastings Center Report 47(1): 10-19.

Ross, L.F., W. Parker, R.M. Veatch, S.E. Gentry, and J.R. Thistlethwaite, Jr. 2012. Equal opportunity supplemented by fair innings: Equity and efficiency in allocating deceased donor kidneys. American Journal of Transplantation 12(8): 2115-2124.

Rulli, T., and J. Millum. 2016. Rescuing the duty to rescue. Journal of Medical Ethics 42(4): 260-264.

Ryan, J.E., M. Noeder, C. Burke, S.C. Stubblefield, S. Sulieman, and E.G. Miller. 2019. Denying renal transplantation to an adolescent medical cannabis user: An ethical case study. Pediatric Transplantation 23(5): e13467. 
Schwarze, M.L., C.T. Bradley, and K.J. Brasel. 2010. Surgical "buy-in": The contractual relationship between surgeons and patients that influences decisions regarding life-supporting therapy. Critical Care Medicine 38(3): 843-848.

Snelgrove, R., S. Ng, and K. Devon. 2016. Ethics M\&Ms: Toward a recognition of ethics in everyday practice. Journal of Graduate Medical Education 8(3): 462-464.

Spielman, B., and S. Verhulst. 1997. Non-heart-beating cadaver procurement and the work of ethics committees. Cambridge Quarterly of Healthcare Ethics 6(3): 282-287.

Spike, J. 2001. Cultural diversity and patients with reduced capacity: The use of ethics consultation to advocate for mentally handicapped persons in living organ donation. Theoretical Medicine and Bioethics. 22(6): 519-526.

Stahl, D.L., S. Siddiqui, and N. Sadovnikoff. 2017. Practical ethics for the anesthesiologist: Experiential ICU teaching and goals of care. American Society of Anesthesiology 81(11): 14-16.

Thomas, S.M., P.J. Ford, K.L. Weise, S. Worley, and E. Kodish. 2015. Not just little adults: A review of 102 paediatric ethics consultations. Acta Paediatrica 104(5): 529-534.
Truog, R.D., and F.G. Miller. 2008. The dead donor rule and organ transplantation. New England Journal of Medicine 359(7): 674-675.

Veatch, R.M., J.A. Balint, W. Glannon, and P.J. Cohen. 2007. Just deserts? Hastings Center Report 37(3): 4-6.

Wall, A., G.H. Lee, J. Maldonado, and D. Magnus. 2019. Medical contraindications to transplant listing in the USA: A survey of adult and pediatric heart, kidney, liver, and lung programs. World Journal of Surgery 43(9): 2300-2308.

Weinzimmer, S., S.M. Miller, J.L. Zimmerman, J. Hooker, S. Isidro, and C.R. Bruce. 2014. Critical care nurses' moral distress in end-of-life decision making. Journal of Nursing Education and Practice 4(6): 6-12.

Publisher's note Springer Nature remains neutral with regard to jurisdictional claims in published maps and institutional affiliations. 